\title{
Pengetahuan Perempuan Terhadap Kontrasepsi: Tinjauan Literatur
}

\author{
Eva Yunitasari ${ }^{1}$; Susi Irma Suri ${ }^{2^{*}}$ ) \\ ${ }^{1^{*}, 2}$ Fakultas Kesehatan Universitas Aisyah Pringsewu
}

\section{ARTICLE INFO}

Keyword:

Knowledge

Contraception

Women

\section{*) corresponding author}

Mahasiswa Program Studi Profesi Ners

Fakultas Kesehatan

Universitas Aisyah Pringsewu

Jl. A Yani No. 1 A Tambak Rejo, Wonodadi, Kec. Pringsewu, Kabupaten Pringsewu, Lampung 35372

Email:

susi.irmasuri@yahoo.com

https://doi.org/10.47679/makein.011.62000002

\begin{abstract}
A B S T R A C T
Program Family Planning, according to WHO (World Health Organization ) in and wife to. avoid births were unwanted, and regulat the distribution of birth,as children in the family. And Many women were difficulties in determining contraception because of ignorance about the requirements and safety contraception is There are several things that can affect some mothers in selecting a tool of contracepion were excluded by level of education, economy, rates of service, approval pasangaan , opinions and knowledge. There are several things that can affect some mothers in selecting a tool of contracepion were excluded by level ofeducation ,economy, rates of service, approval pasangaan , opinions and knowledge. This study aims to examine the results various studies from several journals about maternal knowledge about contraception. The method of research it is Literature Review . the journal used for the literature review last five years 2015-2020. This research was conducted on June 22, 2012 in Gunung Tiga Village, East Lampung Regency. Design studies are taken in search scientific. This is Mixmethos Subjects in this study were post partum mothers. From the study of literature review be in seen in mothers who are knowledgeable, education as well as the mother's attitude then it is rational mother in using the tool of contraception. compared with someonewho studies less then people are going to be difficult to digest and accept the information that he obtained. In a literature review on 10 journal is that discusses about the knowledge of mothers with contraception can not it results that there is a relationship between knowledge, education and attitude and family support to mothers who use contraception. Can develop this research in the family nursing phase in the village by increasing health services in providing counseling or providing information on more effective contraception.
\end{abstract}

\section{PENDAHULUAN}

Program Keluarga Berencana menurut WHO (World Health Organization) 2012. adalah tindakan yang membantu pasangan suami istri untuk menghindari kelahiran yang tidak diinginkan, dan mengatur jarak kelahiran, serta menentukan jumlah anak di dalam keluarga . Berdasarkan data WHO (World Health Organization) Dalam BKKBN tahun 2016 penggunaan kontrasepsi telah meningkat dibagian dunia , terutama di asia dan di amerika latin dan telah meningkat tidak signifikan dari $54 \%$ tahun 1990 menjadi $57,4 \%$ pada tahun 2015 secara regional, proporsi usia subur 15 -49 tahun melaporkan penggunaan metode telah meningkat antara tahun 2008 - 2015. Di afrika dari 23,6 menjadi $8,5 \%$ di asia telah meningkat dari $60,9 \%$ menjadi
$61,8 \%$ sedangkan di amerika latin dan karambia tetap stabil di $66,7 \%$ (WHO 2016).

Menurut profil kesehatan indonesia tahun 2016 presentase KB sebesar 74,8\% dan presntase dan presentase KB tidak aktif sebesar $12,77 \%$, sedangkan di NTT pada PUS berjumlah 703,754 pasangan yang terdiri dari pasangan usia subur yang mengikuti program KB sebesar 445.037(63,24\%) pasangan usia subur yang tidak mengikuti program KB sebesar 141.857 (20.16\%) pasangan (Kemenkes 2016). Dan sedangkan cakupan peserta KB aktif di provinsi lampung pada tahun 2015 sebesar 71,14\% meningkat bila bandingkan tahun sebelumnya, telah mencapai target sebesar $70 \%$ yang 
dimana berarti masih dibawah SPM (100\%) (Dinas Kesehatan Provinsi Lampung 2016 dalam lia agraini 2019).

Banyak wanita yang mengalami kesulitan dalam menentukan kontrasepsi hal ini karena ketidaktahuan tentang persyaratan dan keamanan kontrasepsi tersebut. Ada beberapa hal yang dapat mempengaruhi seseorang ibu dalam memilih alat kontrasepsi diantaranya adalah usia tingkat pendidikan, ekonomi , tarif pelayanan, persetujuan pasangaan ,pendapat dan pengetahuan (Handayani dalam Dinda 2019).

\section{METODE}

Metode penelitian ini adalah Literature Review atau tinjauan pustaka. Studi literature review adalah cara yang dipakai untuk megumpulkan data atau sumber yang berhubungan pada sebuah topik tertentu yang bisa didapat dari berbagai sumber seperti jurnal, buku, internet (google scholar), dan pustaka lain serta yang dipakai untuk literature riview lima tahu terakhir 2015-2020. Analisis yang digunakan menggunakan analisis isi jurnal, kemudian dilakukan koding terhadap isi jurnal yang direview menggunakan kategori psikospiritual Data yang sudah terkumpul kemudian dicari persamaan dan perbedaannya lalu dibahas untuk menarik kesimpulan. Penelitian ini dilakukan Tgl 22 Juni 2012 Di Desa Gunung Tiga Kabupaten Lampung Timur. Subjek dalam penelitian ini ibu postpartum 14 hari. Teknik pengumpulan data menggunakan lembar pengkajian dan data yang digunakan dalam penelitian berasal dari hasil - hasil penelitian yang sudah dilakukan dan diterbirbitkan dalam jurnal nasional dan internasional.

\section{HASIL DAN PEMBAHASAN}

\section{Pembahasan hasil telaah Evidance base berdasarkan teori} dan hasil penelitian

Pengetahuan tentang metode kontrasepsi adalah tahu tentang ragam metode kontrasepsi yang tersedia meliputi keamanan dan cara pemakaian metodemetode tersebut, kontrasepsi yang mereka pilih, efek samping, dan komplikasinya (Pendit, 2007). Ada hubungan yang bermakna antara pengetahuan dengan penggunaan Metode Kontrasepsi Efektif Terpilih di Puskesmas Lolak Kabupaten Bolaang Mongondow. Ada hubungan yang bermakna antara pendidikan dengan penggunaan Metode Kontrasepsi Efektif Terpilih di Puskesmas Lolak Kabupaten Bolaang Mongondow (Nourita M, Sandra T, Syull K 2015).

Hasil menunjukan masih bahwa ibu yang berpengetahuan kesehatan reproduksi masih ada yang rendah dan Berdasarkan hasil dari pasangan usia subur yang memakai kontrasepsi hormonal lebih tinggi dari pada pasangan usia subur dengan penggunaan kontrasepsi non hormonal. Hal ini dikarenakan kurangnya informasi mengenai alat kontrasepsi beserta efek samping, kontraindikasi, kekurangan, dan kelebihan. Dan dikarenakan ibu usia subur jarang mengikuti penyuluhan. Dengan melihat dari hasil penelitian, pemilihan penggunaan kontrasepsi hormonal paling banyak digunakan dari pada penggunaan kontrasepsi non hormonal." (Devi P 2015 ).

Hasil penelitian menunjukan bahwa terdapat hubungan yang bermakna antara pengetahuan dan penggunakan alat kontrasepsi Implant. dilihat dari Odds Ratio ibu yang pengetahuannya cukup beresiko 7 kali lebih besar untuk tidak menggunakan alat kontrasepsi implant dibandingkan dengan ibu yang pengetahuannya baik. Sedangkan berdasarkan presentase berdasarkan pendidikan pendidikan rendah yang tidak menggunakan alat kontrasepsi Implant sebesar (98,5\%). Yang artinya ibu yang pendidikan rendah lebih berisiko untuk tidak menggunakan alat kontrasepsi implant dibandingkan dengan ibu yang pendidikan baik. Sehingga sebagai tenaga kesehatan dan petugas lapangan KB untuk memberikan penyuluhan dan konseling kepada ibu tentang alat kontrasepsi terutama alat kontrasepsi implant dengan menggunakan alat bantu media seperti poster, leaflet maupun Alat Bantu Pengambilan Keputusan (ABPK) ber-KB. Hal ini sesuai dengan penelitian Suprida (2013) yang menunjukan hubungan yang bermakna antara pendidikan dengan pemakaian implant. Dari hasil penelitian ini bahwa ada hubungan yang bermakna antara pendidikan dengan pemilihan kontrasepsi implant dan ada hubungan yang bermakna antara umur ibu dengan pemilihan kontrasepsi implant. dan pada dukungan keluarga menunjukan 100\% keluarga tidak mendukung penggunaan kontrasepsi implant. berarti dari hasil tersebut dapat dilihat dukungan keluarga masih rendah sehingga sebagai petugas kesehatan harus mengikut sertakan keluarga terutama suami dalam memberikan penyuluhan dan konseling $\mathrm{KB}$ agar ibu mendapatkan dukungan keluarga.. (Erlina E Dan fitria . 2017).

Hasil penelitian tersebut menun-jukkan bahwa sebagian besar ibu nifas yang menjadi responden penelitian di RSUD Surakarta memiliki tingkat penge-tahuan yang cukup tentang kontrasepsi metode amenore laktasi

dimana responden dapat menjawab pertanyaan mengenai pe-ngertian, indikasi, kontraindikasi, keuntu-ngan, keterbatasan, cara kerja dan instruk-si bagi ibu (Sri Mulyani 2018). hasil penelitian menggunakan uji beda dua mean dependen menunjukan terdapat peningkatan pengetahuan jumlah responden yang memiliki pengetahuan tinggi antara sebelum dan sesudah pendidikan kesehatan (Cristina, rina, Yolanda 2015).Hasil penelitian ini membuktikan bahwa penyuluhan kesehatan yang dilakukan untuk Wanita Usia Subur (PUS) mempunyai pengaruh.( Ikhwan , doni, kudnandar 2019). Penelitian ini sejalan dengan penelitian Maeno dkk. (2013) yang menyatakan bahwa IPE membantu siswa dalam meningkatkan pemahaman mereka tentang pekerjaan interprofesional, meskipun sistem perawatan kesehatan dan sistem pendidikan berbeda dengan negara barat, namun pendidikan interpersonal di jepang dan negara lain akan serupa dengan yang terjadi di negara barat.

Berdasarkan hasil penelitian didapatkan bahwa pengetahuan tentang akseptor aksekptor KB tentang sisi efek dari suntikan keluarga berencana 3 bulan dibagi menjadi 2 kategori yaitu baik dan terbatas dan yang memiliki efek samping sebanyak $71 \%$ dan tidak mengalami efek samping $29 \%$. Banyak akseptor kontrasepsi mengalami efek samping yang kenaikan berat badan gangguan menstruasi, dan mengalai kecemasan dan lain- lain, upaya dalam mengatasi kecemasan dapat melakukan dengan menggunakan dukungan sosial dan spritual, memberikan dukungan pada ibu untuk mendapatkan suntikan 3 bulan . (Venny 2017).. Dalam penelitian ini sejalan dengan penelitian Ningsih (2010) yang memeriksa 10 akseptor yang menggunakan 3 bulan akutansi kontrol kelahiran suntikan 70\% mengeluh gangguan mentruasi, pertambhan berat badan, sakit kepala, dan panjang nya kembalinya kesuburan, dengan gejala kecemasan, wajah keriput, kekhawatiran ,perasaan menjadi tidak aman. Ini menujukan bahwa kecemasan masih tinggi dalam 3 bulan akseptor karena kurangnya penegtahaun tentang efek samping depo medroxprogesterone acetat

Hasil dari penelitian ini menujukan bahwa terdapat hubungan antara pelayanan kesehatan post partum dan 
kontrasepsi setelah melahirkan di indonesia. karena tingkat rendah kontrasepsi cakupan setelah kelahiran (Arantika 2018). Hasil penelitian ini sejalan dengan penelitian Agustina dan Nawati yang menyatakan bahwa ada kenecendrungan untuk post partum ibu untuk melakukan kunjungan nifas yang baik, untuk menjadi akseptor KB pasca-salin. Salah satu layanan kesehatan yang diberikan selama priode post partum adalah memberikan konseling kepada ibu. Berdasarkan hasil penelitian pada pengetahaun , sikap dan praktek kontrasepsi diantara wanita hamil pernah mendengar tentang kontrasepsi Dengan hasil penelitian ini menunjukan bahwa pengguna kontrasepsi implan banyak digunkana oleh lansia karena usia ,sehingga responden berasumsi bahwa usia mereka bertambah dan bisa mengurangi ingatan mereka akan rasa takut lupa minum pil ( Fitriana , Toto , Hendri 2020). Hasil penelitian ini sejalan dengan penelitian dilakukan oleh radita (2014) dalam penelitian yang bertujuan untuk menemukan hubungan paritas ibu dengan alasan bahwa akseptor kontrasepsi pil menggantikan dengan ditanamkan kontrasepsi di puskesmas kota surakarta.

Dalam literature review pada 10 jurnal ini yang membahasa tentang pengetahuan ibu dengan kontrasepsi didapatkan hasil bahwa terdapat hubungan antara pengetahuan, pendidikan dan sikap serta dukungan keluarga pada ibu pengguna kontrasepsi, Menurut peneliti sebelumnnya (Martaadisoebrata, 2005). Mengubah atau meningkatkan pengetahuan dapat dilakukan melalui pendidikan. Pendidikan yang dimaksudkan dalam program KB adalah pendidikan nonformal atau pendidikan jangka pendek, karena perubahan sikap dan perilaku dalam ber-KB adalah cara memahami pentingnya ber-KB. Oleh sebab itu melalui program KIE (Komunikasi, Informasi, Edukasi ) dapat menembus budaya masyarakat sehingga menimbulkan kesadaran tentang manfaat ber-KB .

\section{DAFTAR PUSTAKA}

Arantika, MP,. (2018). Relationship Between Postpartum Health Care With Contraceptive After Childbirth In Indonesia. Alma Ata University .

Ari, W,. Siska.D., (2018). Hubungan Pengetahuan Dan Sikap Ibu Terhadap Penggunaan Kb Metode Kontrasepsi Jangka Panjang (Mkjp) Diwilayah Kerja Puskesmas Peramasan Kabupaten Banjar, Martapura. Fakultas Kesehatan Masyarakat Universitas Islam Kalimantan( Uniska) Mab Banjarmasin.

Anni, MA,. (2016). Faktor - Faktor Yang Berhubungan Dengan Penggunaan Kb Suntik Pada Ibu Usia Kurang Dari 20 Tahun Di Puskesmas Sewoh 1 Bantul. Program Studi Bidan Pendidik Jenjang Diploma Iv : Universitas Aisyiyah Yogyakarta. (Publikasi Ilmiah).

Cristina.K,.Rina.K,. Yolanda.B,. (2015). Pengaruh Penyuluhan Kesehatan Terhadap Pengegahuan Wanita Usia Subur (WUS) Dalam Penmilihan Kontrasepsi Didesa Kalama Darat Kecamatan Tamako Kepulauan Sangihe.Fakultas Kedokteran Universitas Sam Ratulangi.

Devi, Ps,. (2015). Hubungan Pengetahuan Kesehatan Reproduksi Pasangan Usia Subur Dengan Pemilihan Kontrasepsi Keluarga Berencana Di Kecamatan Serengan. Apikes Citra Medika Surakarta.

Elya E., Fitria, A.S (2018). Hubungan Pengetahuan, Pendidikan Dan Dukungan Keluarga Alat Kontrasepsi Implant.Akbid La Tansa Mashiro: Rangkasbitung.
Berdasarkan penelitain dilakukan perbandingan antara penegtahuan penyuluhan kesehatan terhadap pengetahuan wanita usia subur dalam pemilihan kontrasepsi sama - sama mempunyai pengaruh penting dalam memilih alat kontrasepsi.

\section{KESIMPULAN DAN SARAN}

Dari studi literature review dapat di lihat pada ibu yang berpengetahuan, pendidikan , serta sikap ibu, sehingga ibu lebih rasional ibu dalam menggunakan alat kontrasepsi. Dan sikap ibu akan lebih mudah menerima hal-hal baru yang akan dianggap menguntungkan bagi dirinya, dibandingkan dengan seseorang yang pendidikannya kurang maka orang tersebut akan sulit mencerna dan menerima informasi yang dia peroleh.

Pendidikan keperawatan dapat mengembangkan penelitian ini dalam stase keperawatan keluarga didesa dengan meningkatakan pelayanan kesehatan dalam memberikan penyuluhan atau memberikan informasi alat kontrasepsi yang lebih efektik dan hendaknya tenaga kesehatan mampu memberikan saran untuk penggunaan kontrasepsi yang efektif dengan usia ibu dan mengikutsertakan keluarga terutama suami dalam memberikan penyuluhan dan konseling KB agar ibu mendapatkan dukungan keluarga dan dapat berprilaku positif dalam menentukan kontrasepsi yang efektif. Diharapkan ibu dapat memperhatiakan dan mempertimbangkan dalam pemilihan kontrasepsi yang efektif terutama berdasarkan umur ibu. Diharapkan agar dapat melakukan penelitian pengaruh pemberian penyuluhan pada suami tentang penggunaan kontrasepsi pada pasanaga usia subur.
Elfi. SR,. (2018). Hubungan Pengetahuan Dan Tingkat Pendidikan IBU Dengan Penggunaan Metode Kontrasepsi Efektif Terpilih Di Puskesmas AEK Godang Padang Lawas Utara Tahun 2018. Insitut Kesehatan Helvetia: Medan .

Fitriana, A,.Tato,. handry.D.(2020). Factors Affecting The Reason Mother Replace Pill Contraception With Implant Contraception Inthe UPTD Puskesmas Of Kemalaraja : East Baturajasub District OKU District In 2019. Lecture Of Dapartemen Of Nursing, Akper Al-Ma'arif Baturaja: Lecture Of The Poltekes Kemenkes East Kalimantan.

Ikhwan. Yk,.Doni.An,.Kusnanda,. (2019). Focus Grup Discussion (Fgd) Interprofessional Education (Ipe) Sebagai Alternatif Peningkatan Pengetahuan Tenaga Kesehatan Tentang Kontrasepsi Oral Dan Suntik Dikota Bandung.Study Farmasi Universitas Institusi Bandung.

Lia, A,.(2019).Faktor - Faktor Yang Berhubungan Dengan Pengguna Metode Kontrasepsi Efektif Pada Pasangan Usia Subur. Dalam. Dines Kesehatan Provinsi Lampung. Upload: (2016). Http://Dinkes . Lampungprov.Go.Id/2016/Print=Search.

Naorita M, Sandra, Syull K. (2015). Hubungan Pengetahuan Dan Tingkat Pendidikan Dengan Penggunaan Kontrasepsi Metode Kontrasepsi Terpilih Efektif. Jurusan Kebidanan Poltekes Kemenkes Manado.

Nursalam. (2016). Metodelogi Penelitian Ilmu Keperawatan . Pedekatan Praktis .Ed.4. Jakarta : Salemba Medika 
Notoatmojo, S,. (2012).Metode Penelitian Kesehatan. Jakarta : Rineka Cipta.

Paramita, DO,.(2016). Hubungan Tingkat Pengetahuan Ibu Tentang Kontrasepsi Dengan Metode Pemilihan Kontrasepsi Hormonaldan Non Harmonal Di Desa Ngalian Kabupaten Wonosobo. Jurusan Program Studi Pendidikan Kedokteran . Universitas

Sri.M,. (2018). Hubungan Pengetahuan Dan Sikap Ibu Post Partum Terhadap Metode Kontrasepsi Amneore Laktasi (MAL).Fakultas Kedokteran Universitas Sebelas Maret Surakarta.

Venny.R,. (2019) Relationship Between Knowledge Of Contraception Acceptors With Sede Efects Of The Three Mounth Injection Family Palnning In Kambesko Health Center 2017.Diploma 3of Midwifery Indragiri Academic Rengat Indonesia.

World Health Organization (WHO). (2016). Dalam. BKKBN , 2016. Laporan pencapaian. 